\title{
Battery Technologies for Grid-Level Large-Scale Electrical Energy Storage
}

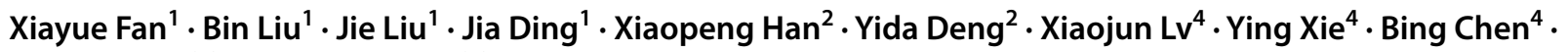 \\ Wenbin $\mathrm{Hu}^{1,2,3}$. Cheng Zhong ${ }^{1,2,3}$
}

Received: 11 November 2019 / Revised: 3 December 2019 / Accepted: 10 December 2019 / Published online: 8 January 2020

(c) The Author(s) 2020

\begin{abstract}
Grid-level large-scale electrical energy storage (GLEES) is an essential approach for balancing the supply-demand of electricity generation, distribution, and usage. Compared with conventional energy storage methods, battery technologies are desirable energy storage devices for GLEES due to their easy modularization, rapid response, flexible installation, and short construction cycles. In general, battery energy storage technologies are expected to meet the requirements of GLEES such as peak shaving and load leveling, voltage and frequency regulation, and emergency response, which are highlighted in this perspective. Furthermore, several types of battery technologies, including lead-acid, nickel-cadmium, nickel-metal hydride, sodium-sulfur, lithium-ion, and flow batteries, are discussed in detail for the application of GLEES. Moreover, some possible developing directions to facilitate efforts in this area are presented to establish a perspective on battery technology, provide a road map for guiding future studies, and promote the commercial application of batteries for GLEES.
\end{abstract}

Keywords Battery technologies · Grid-level large-scale electrical energy storage $\cdot$ Peak shaving and load leveling $\cdot$ Voltage and frequency regulation $\cdot$ Emergency response

\section{Introduction}

Electricity is one of the most dominant forms of energy that is utilized and has become increasingly required since the electrical age began. However, the instantaneous demand for electrical energy varies considerably daily and seasonally. Energy storage technologies are of great importance to balance the supply and demand of electricity generation,

Cheng Zhong

cheng.zhong@tju.edu.cn

1 Key Laboratory of Advanced Ceramics and Machining Technology (Ministry of Education), School of Materials Science and Engineering, Tianjin University, Tianjin 300072, China

2 Tianjin Key Laboratory of Composite and Functional Materials, School of Materials Science and Engineering, Tianjin University, Tianjin 300072, China

3 Joint School of National University of Singapore and Tianjin University, International Campus of Tianjin University, Binhai New City, Fuzhou 350207, China

4 State Grid Zhejiang Zhedian Tendering Consulting Co., Ltd., Hangzhou 310000, China distribution, and usage. For stationary application, grid-level large-scale electrical energy storage (GLEES) is an electricity transformation process that converts the energy from a grid-scale power network into a storable form that can be converted back to electrical energy once needed [1]. As a just-in-time supply system, GLEES plays a fundamental role in avoiding excessive power generation capacity to meet short-term peak electricity need, which is mainly oriented to alleviate the power supply gap of the grid, improve the utilization efficiency of power generation equipment, avoid frequent start and stop of the thermal power unit, reduce the investment in power grid construction, and ensure the safe and stable operation of the power grid system.

So far, several types of energy storage approaches have been investigated and explored, such as secondary battery technologies and supercapacitors, flow batteries, fuel cells, flywheels, compressed air energy storage, thermal energy storage, and pumped hydroelectric power [2-9]. Among them, traditional energy storage technologies usually have low energy efficiency, require immense capital investment, and have location-dependent problems. In comparison, batteries, including secondary batteries and flow batteries, are mature energy storage devices that are 
known for modularization, rapid response, flexible installation, and short construction cycles [10, 11]. Generally, battery energy storage technologies used in GLEES are expected to meet the demands of peak shaving and load leveling, voltage and frequency regulation, and emergency energy storage. Peak shaving and load leveling refer to processes during which the battery energy storage system stores electrical energy (charging process) under low electrical load and releases the stored electrical energy (discharging process) under high electrical load [12]. Voltage and frequency regulation is related to a process where batteries balance load and power of the grid network by charging and discharging to provide regulation power to the grid with fast response time [13]. Emergency energy storage is associated with the requirements of backup devices with a millisecond-level quick response and can achieve full power discharge in any state with a wide-scale active power shortage.

So far, numerous battery energy storage technologies have been developed to fulfill the demands of various fields based on specific application requirements, such as energy density, specific capacity, discharge performance, power output, response time, cycle life, safety, and cost. Various excellent review articles focus on the fundamentals and investigation of batteries [14-23], which will not be discussed in detail in this perspective. However, few studies focus on the battery energy storage technologies for application in GLEES, which depends more on the corresponding specific application requirements of grid-scale energy storage, including regional power grid peak shaving and load leveling, frequency modulation, voltage regulation, and emergency response. On the basis of these demands, battery energy storage technologies with rapid response, low cost, long lifetime, high power, and energy efficiency can be distributed throughout the grid and therefore are desirable for utilization in GLEES [24]. However, some trade-offs often exist among different properties and no existing batteries can meet all the requirements.

In this perspective, several promising battery technologies (e.g., lead-acid batteries, nickel-cadmium [Ni-Cd] batteries, nickel-metal hydride [Ni-MH] batteries, sodium-sulfur [Na-S] batteries, lithium-ion [Li-ion] batteries, flow batteries) for GLEES are presented and analyzed in detail in terms of their operating mechanism, battery construction and design, and corresponding advantages and disadvantages. Their promising properties on the application in GLEES are also highlighted to build a bridge between battery performances and practical uses in GLEES. With the technological innovation and successful development of newly developed batteries, the efficiency, energy density, and lifetime of batteries have been improved significantly. However, many challenges exist for each type of batteries, which will be documented in the final section. Possible research directions to overcome the challenges are proposed to promote efforts in this field.

\section{Grid-Level Large-Scale Electrical Energy Storage}

Given that balancing the demand and supply of electricity generation, distribution, and usage is becoming increasingly important, GLEES is critical to avert building excessive energy generation capacity for fulfilling the requirement of short-term peak electrical energy demand. GLEES refers to an electricity transformation process of converting electrical energy from a grid-scale power network into a storable form that can be converted back when needed [1]. According to the Electricity Storage Association (ESA; http://www. electricitystorage.org), several energy storage approaches deployed around the world have been developed and can be categorized into (1) secondary battery technologies, (2) flow batteries, (3) supercapacitors, (4) flywheels, (5) compressed air energy storage, (6) thermal energy storage, and (7) pumped hydroelectric power [25]. Batteries, including secondary batteries and flow batteries, which are known for their modularization, rapid response, flexible installation, and short construction cycles, are regarded as promising energy storage technologies for GLEES (Fig. 1) [10]. In general, the battery technologies utilized in GLEES are expected to meet the following demands of GLEES: (1) peak shaving and load leveling; (2) voltage and frequency regulation; and (3) emergency energy storage.

Given that the electrical power demand varies considerably daily, seasonally, and emergently, especially the large peak-to-valley difference between day and night, peak shaving and load leveling are efficient methods to achieve energy saving and emission reduction. During the peak shaving process, the energy storage devices are charged while the system load of the grid network is low, which will be discharged to remove only the peaks of the load. During the load leveling process, the same process proceeds to aim to flatten the load instead of removing the system's peaks [12]. The peak shaving and load leveling processes for GLEES are shown in Fig. 2. To achieve peak shaving and load leveling, battery energy storage technology is utilized to cut the peaks and fill the valleys that are charged with the generated energy of the grid during off-peak demand, and then, the electricity is injected into the grid under high electrical energy demand [27]. This approach will greatly reduce the peak-to-valley difference of electricity consumption without investing in rebuilding power plants and avoid the overall economic decline of the generator set caused by the excessive idle capacity of the system at the valley value.

Generally, energy and power are strongly reflected in the increase or decrease in the voltage and frequency in 


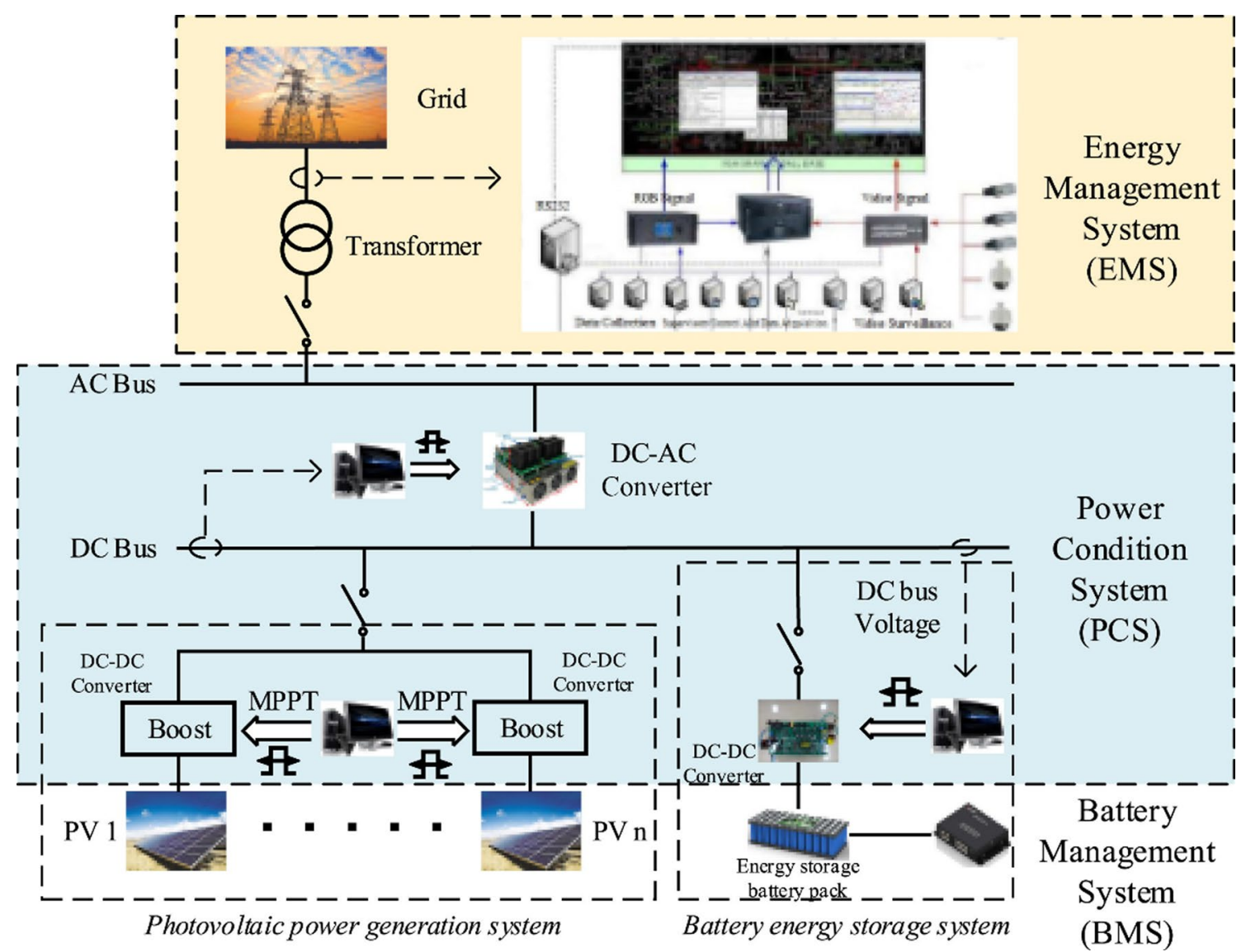

Fig. 1 Schematic of the battery energy storage system in GLEES. Reproduced with permission [26]. Copyright 2018, Elsevier

the grid. Therefore, the voltage and frequency regulation function addresses the balance between the network's load and the generated power, which is one of the most efficient ways to achieve grid stability; this concept is the premise of real-time electric power and energy balance [28]. Voltage regulation is generally carried out by reverse voltage regulation, smooth voltage regulation, and constant voltage regulation. The basic method is to use the reactive power generating device for compensation, including adjusting the generator terminal voltage, changing the transformer ratio, capacitance compensation, and static compensator compensation. In addition, frequency regulation is typically achieved by varying the power output from the energy storage devices connected to the grid, which is nominally 60 or $50 \mathrm{~Hz}$ in most networks worldwide. Specifically, the frequency of grid system can be adjusted by increasing and decreasing the rotor speed of the rotating machines (e.g., hydro generators, large diesel generators, motors) [28]. Battery energy storage technology is an effective approach for the voltage and frequency regulation, which provides regulation power to the grid by charging and discharging with a fast response time $(<20 \mathrm{~ms})$ that is much shorter than that of traditional energy storage approaches (sec-min) [10, 13]. Given the real-time, short-term, random, and unpredictable issues of the grid, battery energy storage technology is a critical guarantee for the safety and reliability of GLEES.

Security of the grid system is related to the smooth development of the national economy and social stability because accidents in the grid system will seriously affect social production and people's lives. For example, the "8.14" blackout in the USA and Canada in 2003 resulted in a total of $29 \mathrm{~h}$ of power outages with a loss of $61.8 \mathrm{GW}$ of electricity and left 50 million people without power supply [29]. The November 4, 2006, large-scale power outages in Europe caused a load loss of $16.72 \mathrm{GW}$ and affected the life of 10 million people [30]. Such incidents around the world have raised awareness of the need to strengthen emergency energy storage systems. Emergency energy storage requires a millisecond-level quick response to achieve full power discharge in any state with a large area of active power shortage. Battery energy storage, which is known for its fast response time during charging and discharging, is an effective technology for emergency energy storage in GLEES. 

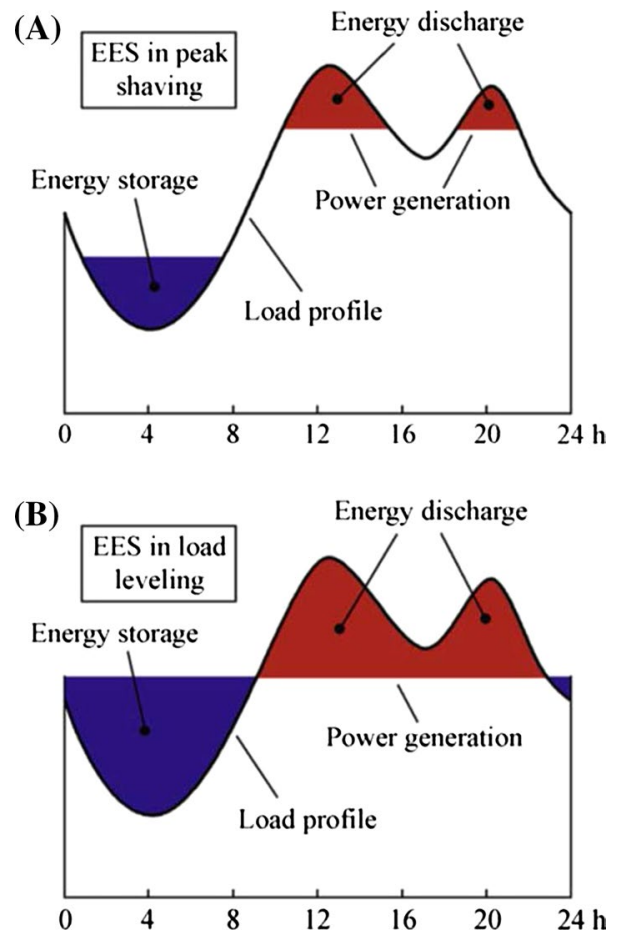

Fig. 2 Load profile of GLEES. a Electrical energy storage in peak shaving. b Electrical energy storage in load leveling. Reproduced with permission [1]. Copyright 2009, Elsevier

\section{Battery Technologies for Grid-Level Large-Scale Electrical Energy Storage}

As mentioned above, GLEES is critical to meet the balance of electricity demand and supply in the grid. To meet requirements, energy storage technologies with rapid response, long cycle life, low cost, and high power and energy efficiency are needed [24]. Unlike conventional energy storage approaches (e.g., pumped hydroelectric power, compressed air energy storage, thermal energy storage), battery energy storage technologies are promising candidates for GLEES. Batteries are currently regarded as a desirable energy storage system in GLEES with high investment benefits and are known for their high commercial potential, fast response time, modularity, flexible installation, and short construction cycles [26]. To date, various battery technologies have been developed to comply with the increasing interest in GLEES, such as lead-acid batteries, $\mathrm{Ni}-\mathrm{Cd}$ batteries, $\mathrm{Ni}-\mathrm{MH}$ batteries, $\mathrm{Na}-\mathrm{S}$ batteries, Li-ion batteries, and flow batteries. With respect to the application in GLEES, several specific demands related to battery construction need to be given attention, including battery power and energy densities, battery voltage, battery capacity, response time, charge-discharge rates, safety issues, and economic efficiency, which are essential to construct an efficient battery system for GLEES [26].

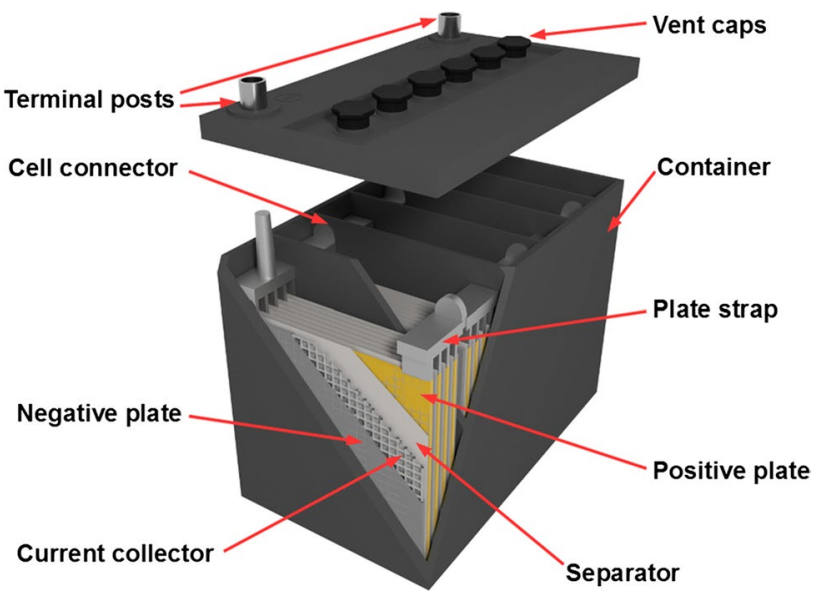

Fig. 3 Schematic of lead-acid batteries. Reproduced with permission [35]. Copyright 2019, Springer

\section{Lead-Acid Batteries}

The lead-acid battery is a battery technology with a long history. Typically, the lead-acid battery consists of lead dioxide $\left(\mathrm{PbO}_{2}\right)$, metallic lead $(\mathrm{Pb})$, and sulfuric acid solution $\left(\mathrm{H}_{2} \mathrm{SO}_{4}\right)$ as the negative electrode, positive electrode, and electrolyte, respectively (Fig. 3) [31]. The lead-acid battery requires a container that is usually made of thermoplastics (e.g., acrylonitrile-butadiene-styrene, styrene-acrylonitrile resin, polycarbonate, polyvinyl chloride, polyolefin) [32]. The operation of lead-acid secondary battery is based on Eq. (1) [33].

$\mathrm{Pb}+\mathrm{PbO}_{2}+2 \mathrm{H}_{2} \mathrm{SO}_{4} \Leftrightarrow 2 \mathrm{PbSO}_{4}+2 \mathrm{H}_{2} \mathrm{O} \quad E^{0}=2.04 \mathrm{~V}$

Several kinds of lead-acid batteries have been developed, such as the flooded battery (which requires regular topping up with distilled water) and the sealed maintenance-free battery, including the valve-regulated lead-acid (VRLA) battery and gelled/absorbed electrolyte-based lead-acid battery [1]. In practice, the lead-acid battery has an electrical turnaround efficiency of $75-80 \%$ with an energy density of 30-50 Wh/ $\mathrm{kg}$. The nominal voltage of the lead-acid battery is $\sim 2 \mathrm{~V}$ [34]. Furthermore, the lead-acid battery has a low price $(\$ 300-600 / \mathrm{kWh})$, is easy to manufacture, has maintenance-free designs, and allows easy recycling of the battery components $(>97 \%$ of all battery lead can be recycled) [32]. However, the practical application of lead-acid battery for GLEES is limited because of the relatively short lifetime (500-1000 cycles) and its low energy density resulting from the inherent high density of lead. In addition, a thermal management system is required for lead-acid batteries due to their poor lowtemperature performance. The major advantages and disadvantages of lead-acid batteries are listed in Table 1. For 
Table 1 Major advantages and disadvantages of different types of batteries [32]

\begin{tabular}{|c|c|c|}
\hline Battery type & Advantages & Disadvantages \\
\hline Lead-acid & $\begin{array}{l}\text { Low cost } \\
\text { Availability of large quantities with various sizes and designs } \\
\text { High battery voltage } \\
\text { Good high-rate performance } \\
\text { Good charge retention for intermittent charge applications } \\
\text { Availability in maintenance-free designs } \\
\text { High recyclability of battery components }\end{array}$ & $\begin{array}{l}\text { Limited energy density } \\
\text { Relatively short cycle life } \\
\text { Irreversible polarization of electrodes (sulfation generation } \\
\text { after long-term storage in a discharged condition) } \\
\text { Potential hydrogen evolution }\end{array}$ \\
\hline $\mathrm{Ni}-\mathrm{Cd}$ & $\begin{array}{l}\text { Long cycle life } \\
\text { Ability to withstand electrical and physical abuse } \\
\text { Excellent long-term storage } \\
\text { Low maintenance }\end{array}$ & $\begin{array}{l}\text { Limited energy density } \\
\text { Relatively high cost (compared with lead-acid batteries) } \\
\text { Memory effect } \\
\text { Containing toxic element cadmium } \\
\text { Containing caustic alkaline electrolyte }\end{array}$ \\
\hline $\mathrm{Ni}-\mathrm{MH}$ & $\begin{array}{l}\text { Relatively high energy density } \\
\text { Good high-temperature capability } \\
\text { Good high-rate capability } \\
\text { Long cycle life } \\
\text { Long shelf life } \\
\text { Good charge retention } \\
\text { Rapid recharge capability } \\
\text { Sealed maintenance-free design } \\
\text { High safety which can be operated at high voltage } \\
\text { Safety in charge and discharge, including tolerance to abu- } \\
\text { sive overcharge and overdischarge } \\
\text { Environmentally acceptable and recyclable materials }\end{array}$ & $\begin{array}{l}\text { Relatively high cost (compared with lead-acid batteries) } \\
\text { Decreased performance at low temperature }\end{array}$ \\
\hline $\mathrm{Na}-\mathrm{S}$ & $\begin{array}{l}\text { Relatively high energy density } \\
\text { Relatively long cycle life } \\
\text { Pulse power capability } \\
\text { High self-discharge resistance }\end{array}$ & $\begin{array}{l}\text { High working temperature } \\
\text { High cost }\end{array}$ \\
\hline Li-ion & $\begin{array}{l}\text { Relatively high energy density } \\
\text { Low maintenance fee } \\
\text { Broad operation temperature range } \\
\text { Long cycle life } \\
\text { Long shelf life } \\
\text { Rapid charge capability } \\
\text { No memory effects } \\
\text { Many possible chemistries offer design flexibility }\end{array}$ & $\begin{array}{l}\text { Relatively high cost } \\
\text { Poor high-temperature performance } \\
\text { Requirement of protective circuitry }\end{array}$ \\
\hline Zinc-bromine & $\begin{array}{l}\text { Relatively high energy density } \\
\text { High design flexibility } \\
\text { Relatively low cost } \\
\text { Capability of rapid charge. } \\
\text { Capability of } 100 \% \text { depth of discharge }\end{array}$ & $\begin{array}{l}\text { Potential zinc dendrite formation } \\
\text { Poor cycle life }\end{array}$ \\
\hline Vanadium redox & $\begin{array}{l}\text { Long cycle life } \\
\text { High safety } \\
\text { Low operation cost and maintenance } \\
\text { Capability of deep discharge }\end{array}$ & $\begin{array}{l}\text { Requirement of large space } \\
\text { Relatively low energy density }\end{array}$ \\
\hline Polysulfide bromide & Fast response time & $\begin{array}{l}\text { Limited energy density } \\
\text { Relatively low efficiency } \\
\text { Cross-contamination during the long-term battery operation }\end{array}$ \\
\hline
\end{tabular}

stationary applications, the lead-acid battery is flooded with excess electrolyte to minimize maintenance and the watering interval [32]. In addition, the VRLA stationary battery utilizes the recombination of oxygen and hydrogen released on the positive and negative plates, respectively, to generate water, thereby eliminating the need to add water in conventional lead-acid batteries [25].

\section{Nickel-Cadmium (Ni-Cd) Batteries}

$\mathrm{Ni}-\mathrm{Cd}$ battery is another mature technology with a long history of more than 100 years. In general, Ni-Cd battery is composed of a nickel hydroxide positive electrode, a cadmium hydroxide negative electrode, an alkaline electrolyte, and a separator. An Ni-Cd battery is usually 
assembled with a plastic or metal case that contains a sealing plate equipped with a self-sealing safety valve. The plastic containers for Ni-Cd battery are made from polypropylene, polystyrene, and flame-retarded plastics, which are preferable to the metal-based counterpart and have relatively high corrosion resistance, low weight, and ease of visual control of the electrolyte level [32]. The charge and discharge operation mechanism of Ni-Cd batteries can be presented as the following Eq. (2):

$2 \mathrm{NiOOH}+2 \mathrm{H}_{2} \mathrm{O}+\mathrm{Cd} \Leftrightarrow 2 \mathrm{Ni}(\mathrm{OH})_{2}+\mathrm{Cd}(\mathrm{OH})_{2} \quad E^{0}=1.29 \mathrm{~V}$

$\mathrm{Ni}-\mathrm{Cd}$ batteries have an energy density of 50-75 Wh/ $\mathrm{kg}$ and are known for their relatively long cycle life (2000-2500 cycles), wide operation temperature range, good charge properties, and low maintenance requirements. However, $\mathrm{Ni}-\mathrm{Cd}$ batteries suffer from relatively high cost $(\sim \$ 1000 / \mathrm{kWh})$ due to the expensive manufacturing process, and they contain a toxic heavy metal element $(\mathrm{Cd})$ and are known for the "memory effect." The memory effect of the $\mathrm{Ni}-\mathrm{Cd}$ battery refers to its tendency to adjust the electrical properties to a certain duty cycle that has been subjected for a long period of time; this effect can be properly mitigated by reasonable battery management $[1,32]$. The major advantages and disadvantages of Ni-Cd batteries are shown in Table 1 .

\section{Nickel-Metal Hydride (Ni-MH) Batteries}

$\mathrm{Ni}-\mathrm{MH}$ batteries were first studied in the 1960s and have been on the market for over 20 years as portable and traction batteries [32]. Ni-MH batteries comprise metal hydride anodes (e.g., $\mathrm{AB}_{5}$-type [LaCePrNdNiCoMnAl], $\mathrm{A}_{2} \mathrm{~B}_{7}$-type [LaCePrNdMgNiCoMnAlZr], or $\mathrm{AB}_{2}$-type [VTiZrNiCrCoMnAlSn] metal hydride active materials), nickel hydroxide cathodes, and alkaline electrolytes (e.g., $\mathrm{KOH}, \mathrm{KOH} /$ $\mathrm{LiOH}, \mathrm{KOH} / \mathrm{NaOH} / \mathrm{LiOH}$ ). A separator is usually utilized as the insulator between anodes and cathodes, functions as the medium for absorbing electrolytes, and is composed of synthetic nonwoven material. The battery chemistry of $\mathrm{Ni}-\mathrm{MH}$ batteries is shown in Fig. 4 and described by the following Eq. (3):

$\mathrm{MH}+\mathrm{NiOOH} \Leftrightarrow \mathrm{M}+\mathrm{Ni}(\mathrm{OH})_{2} \quad E^{0}=1.35 \mathrm{~V}$

As for Ni-MH batteries, both the anode and cathode are porous structures with a large surface area, thus providing low internal resistance and high-rate performance capability. The cathode is generally fabricated by impregnating or pasting nickel compounds into the foam nickel or a highly porous sintered substrate, and the anode is a hydrogen-storage-alloy-coated perforated nickel foil or grid. In practice, $\mathrm{Ni}-\mathrm{MH}$ batteries can be utilized in telecommunications, to provide uninterrupted power supply, and to power hybrid electric vehicles due to their high energy and power (40-110 Wh/kg, 200-1200 W/kg) [36], environment
Fig. 4 Schematic of $\mathrm{Ni}-\mathrm{MH}$ batteries. Reproduced with permission [37]. Copyright 2017, Elsevier

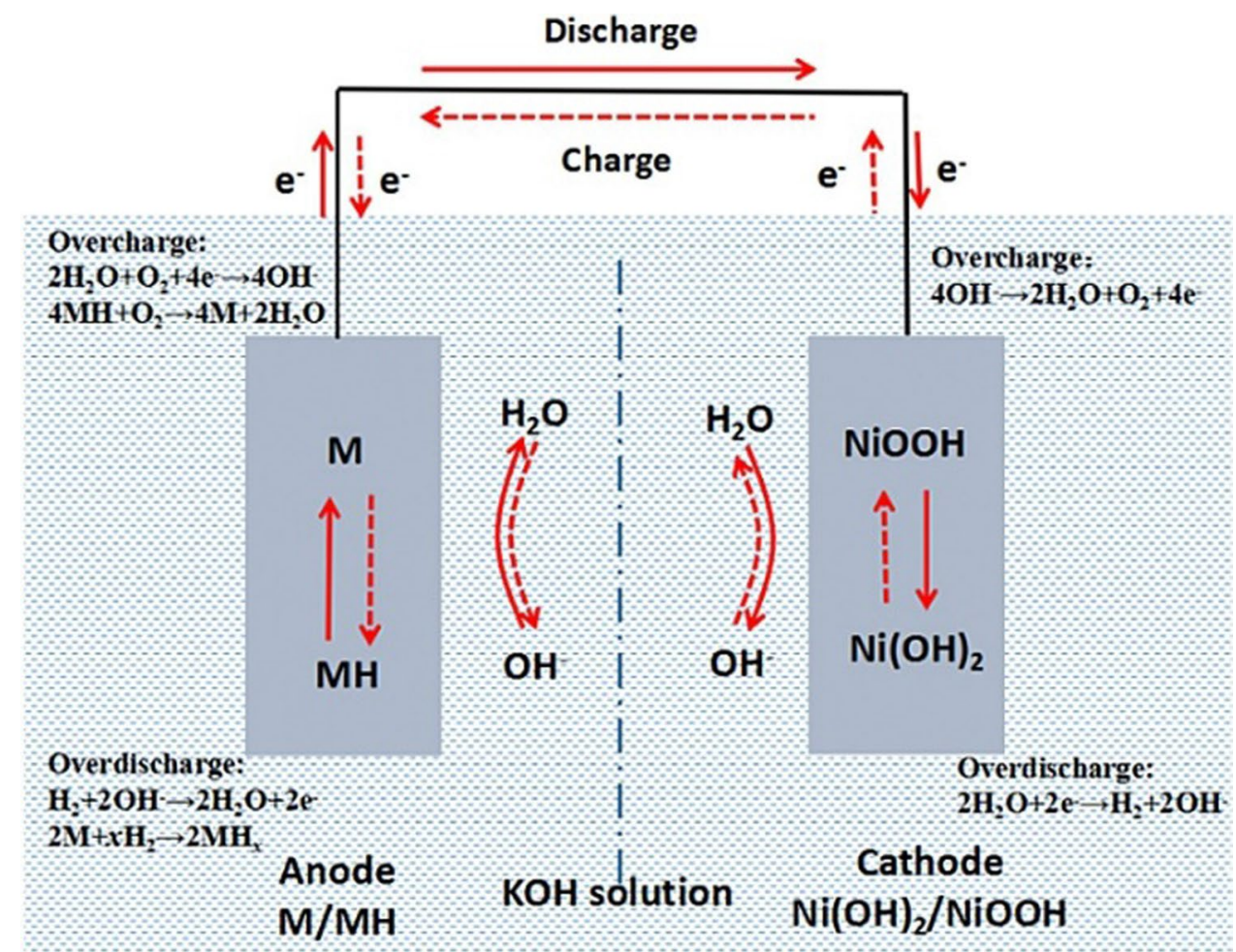


friendliness, wide range of operating temperatures $(-30$ to $70{ }^{\circ} \mathrm{C}$ ), high tolerance to abusive overcharge and overdischarge, long-life characteristics, low maintenance, and low cost [32]. The major advantages and disadvantages of $\mathrm{Ni}-\mathrm{MH}$ batteries are shown in Table 1.

\section{Sodium-Sulfur (Na-S) Batteries}

$\mathrm{Na}-\mathrm{S}$ battery was first invented by Ford in 1967 and is considered as one of the most promising candidates for GLEES. $\mathrm{Na}-\mathrm{S}$ batteries are composed of molten $\mathrm{Na}$ anodes, molten $\mathrm{S}$ cathodes, and $\mathrm{Na}^{+}$-conducting ceramic electrolytes (e.g., $\beta^{\prime \prime}$ $\mathrm{Al}_{2} \mathrm{O}_{3}$ ) under a working temperature of $300-350{ }^{\circ} \mathrm{C}$ (Fig. 5). Considering the insulator nature of $\mathrm{S}$ materials, $\mathrm{S}$ cathodes are generally filled in a conductive porous carbon or graphite felt as current collectors. The casing for $\mathrm{Na}-\mathrm{S}$ batteries is usually made of stainless steel. The charge and discharge battery chemistry of $\mathrm{Na}-\mathrm{S}$ batteries is presented in Eq. (4):

$2 \mathrm{Na}+x \mathrm{~S} \Leftrightarrow \mathrm{Na}_{2} \mathrm{~S}_{x} \quad E^{0}=1.78-2.07 \mathrm{~V}$

$\mathrm{Na}-\mathrm{S}$ battery has a theoretical energy density of $760 \mathrm{Wh} / \mathrm{kg}$, and its practical energy and power density are $150-240 \mathrm{Wh} / \mathrm{kg}$ and $150-230 \mathrm{~W} / \mathrm{kg}$, respectively. Na-S batteries have a relatively long cycle life of typically $\sim 2500$ cycles with an efficiency of 75-90\%. Furthermore, Na-S batteries are capable of pulse power for more than six times their continuous rating (for $30 \mathrm{~s}$ ), thereby making them promising energy storage devices for GLEES in peak shaving and load leveling applications. As a result, the $\mathrm{Na}-\mathrm{S}$ battery is characterized by a relatively high specific energy and power density, high current and rate capacity, high selfdischarge resistance, high electrical efficiency, low vibration,

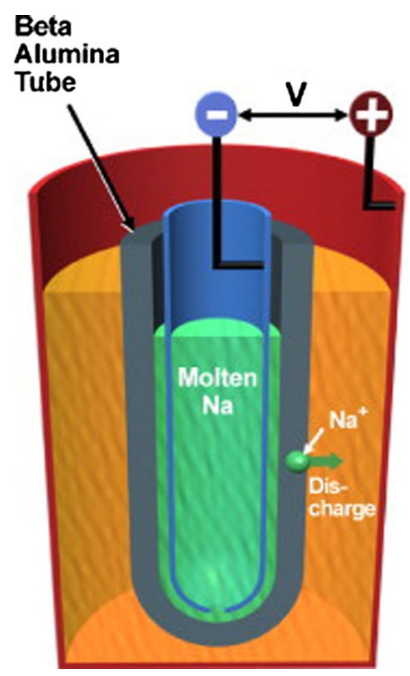

Fig. 5 Schematic of $\mathrm{Na}-\mathrm{S}$ batteries. Reproduced with permission [38]. Copyright 2010, Elsevier low noise, and high environment friendliness. However, the major drawback of $\mathrm{Na}-\mathrm{S}$ batteries is the requirement of a heat source and the highly exothermic reaction between molten $\mathrm{Na}$ and $\mathrm{S}$, thereby increasing the risk of fire. The initial capital cost of $\mathrm{Na}-\mathrm{S}$ batteries is $\sim \$ 350 / \mathrm{kWh}$, and this cost is expected to decline as production capacity expands [1].

\section{Lithium-Ion (Li-Ion) Batteries}

Since the first commercial Li-ion batteries were produced in 1990 by Sony, Li-ion batteries have become one of the most important battery technologies, leading the market in the field of energy storage. As a "rocking chair" battery, Li-ion battery is operated by $\mathrm{Li}^{+}$moving back and forth between two electrodes by inserting or extracting from the interstitial space between atomic layers of electrode materials during discharge-charge processes. Generally, Li-ion batteries comprise positive and negative electrodes and Li-ion-conducting electrolytes (Fig. 6). Typically, positive electrode materials are metal oxides with layered or tunneled structures (e.g., lithium cobalt oxide $\left[\mathrm{LiCoO}_{2}\right]$, lithium manganese oxide $\left[\mathrm{LiMn}_{2} \mathrm{O}_{4}\right], \mathrm{LiFePO}_{4}$ ) on an aluminum current collector. The negative electrode is usually a graphitic carbon on a copper current collector. The electrolyte for Li-ion batteries can be divided into two categories, namely liquid electrolytes and semisolid/solid-state electrolytes. Liquid electrolytes are usually composed of lithium salts (e.g., $\mathrm{LiPF}_{6}, \mathrm{LiBF}_{4}$, $\mathrm{LiN}\left[\mathrm{CF}_{3} \mathrm{SO}_{2}\right]_{2}$ and lithium bis-oxalato borate [LiBOB]) dissolved in organic carbonates (e.g., propylene carbonate, ethylene carbonate, dimethyl carbonate, ethyl methyl carbonate, and diethyl carbonate and their mixtures). The semisolid electrolyte is typically a polymer electrolyte, which is an ion-conducting material composed of lithium salts and high-molecular-weight polymer matrices (e.g., poly(ethylene oxide), polyvinylidene fluoride, polyvinylidene fluoride-hexafluoropropylene) with or without solvents. The solid-state
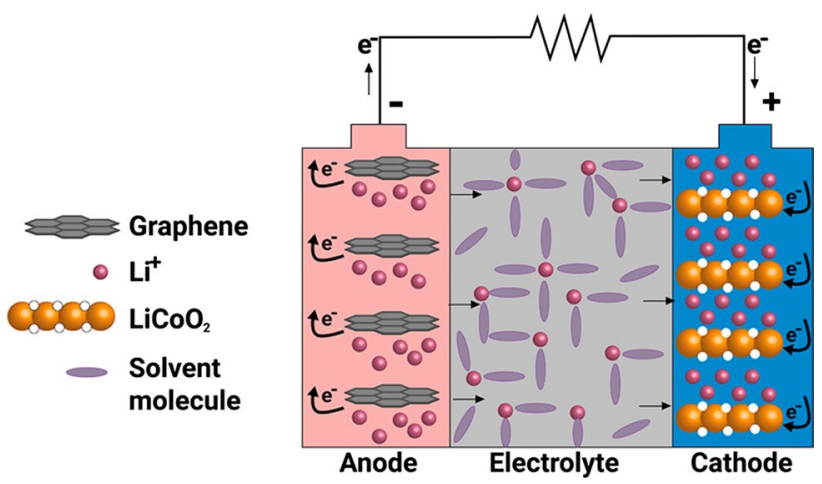

Fig. 6 Schematic of Li-ion batteries. Reproduced with permission [10]. Copyright 2018, Elsevier 
electrolyte refers to the solid-state ion conductor consisting of mobile ions and metal and nonmetal ions that typically form polyhedra with ligands that create the skeleton of the crystal structure. Li-ion conductors based on various crystal structures such as lithium superionic conductor, sodium superionic conductor, argyrodites, garnets, lithium nitrides, lithium hydrides, perovskites, and lithium halides have been extensively investigated [39].

In general, Li-ion batteries are characterized by a long cycle life (higher than 1000 cycles), high efficiency (almost $100 \%$ ), low self-discharge rate (2-8\% per month), and wide operating temperature range (commercial $\mathrm{Li}$-ion batteries may charge between 0 and $45^{\circ} \mathrm{C}$ and discharge between -40 and $65^{\circ} \mathrm{C}$ ). Li-ion batteries can be fabricated into a wide array of sizes and shapes, such as flat or "stacked" prismatic, wound prismatic, spiral-wound cylindrical, and pouch cell designs in small $(0.1 \mathrm{Ah})$ to large $(160 \mathrm{Ah})$ sizes $[1,32]$. The major disadvantages of Li-ion batteries are their relatively low energy density ( $240 \mathrm{Wh} / \mathrm{kg}, 640 \mathrm{Wh} / \mathrm{L})$, potential degradation when discharged below $2 \mathrm{~V}$ at elevated temperatures $\left(65^{\circ} \mathrm{C}\right)$, and the risk of danger when overcharged. Table 1 lists the major advantages and disadvantages of Liion batteries.

\section{Flow Batteries}

Since the 1970s, flow batteries have been explored for the development of electric utility storage applications in the USA and Japan. Flow batteries store energy in electrolyte solutions and contain two redox couples (e.g., $\mathrm{V} / \mathrm{V}, \mathrm{Zn} / \mathrm{Br}_{2}$, $\mathrm{V} / \mathrm{Br}_{2}, \mathrm{~S} / \mathrm{Br}_{2}, \mathrm{Ce} / \mathrm{Zn}, \mathrm{Fe} / \mathrm{Cr}$, and $\mathrm{Pb} / \mathrm{Pb}$ ) flowing through a power battery/reactor with the involvement of reversible chemical reactions (Fig. 7) [1]. In general, two electrolytes of flow batteries are separated in different electrolyte tanks by a cation or anion ion exchange membrane that is impermeable to redox-active species and capable of transporting cations (usually protons or $\mathrm{Na}^{+}$) or anions. Unlike traditional battery technologies, the electrode and electrolyte of flow batteries are separated. In addition, the energy capacity of the flow battery depends on the size of the electrolyte tanks, and its battery power depends on the size of the battery. Generally, three types of flow batteries have been developed in GLEES, namely zinc-bromine flow batteries, vanadium redox batteries, and polysulfide bromide batteries.

The reaction chemistry of zinc-bromine flow batteries is shown as follows:

$\mathrm{Zn}+\mathrm{Br}_{3}^{-} \Leftrightarrow \mathrm{ZnBr}_{2}+\mathrm{Br}^{-} \quad E^{0}=1.85 \mathrm{~V}$

Zinc-bromine flow batteries offer several advantages, such as relatively high specific energy density $(75-85 \mathrm{Wh} / \mathrm{kg})$, high design flexibility, and low cost. However, commercial development of this battery is hindered by the dendrite formation tendency of zinc, poor cycle life, low energy efficiency, and high solubility of bromine in the aqueous zinc bromide electrolyte.

Vanadium redox batteries utilize sulfuric acid containing $\mathrm{V}^{5+} / \mathrm{V}^{4+}$ and $\mathrm{V}^{3+} / \mathrm{V}^{2+}$ redox couples as the positive and negative half-cell electrolytes. The battery chemistry of vanadium redox batteries is based on Eq. (6).

$\mathrm{VO}_{2}^{+}+2 \mathrm{H}^{+}+\mathrm{V}^{2+} \Leftrightarrow \mathrm{VO}^{2+}+\mathrm{H}_{2} \mathrm{O}+\mathrm{V}^{3+} \quad E^{0}=1.26 \mathrm{~V}$

The advantages of vanadium redox batteries are their high battery efficiency (75-85\%), long lifetime (12000-14000 cycles), high safety, low operating cost, and easy maintenance. Furthermore, vanadium redox batteries are capable of deep discharge and are suitable for stationary applications.
Fig. 7 Schematic of flow batteries. Reproduced with permission [40]. Copyright 2006, Elsevier

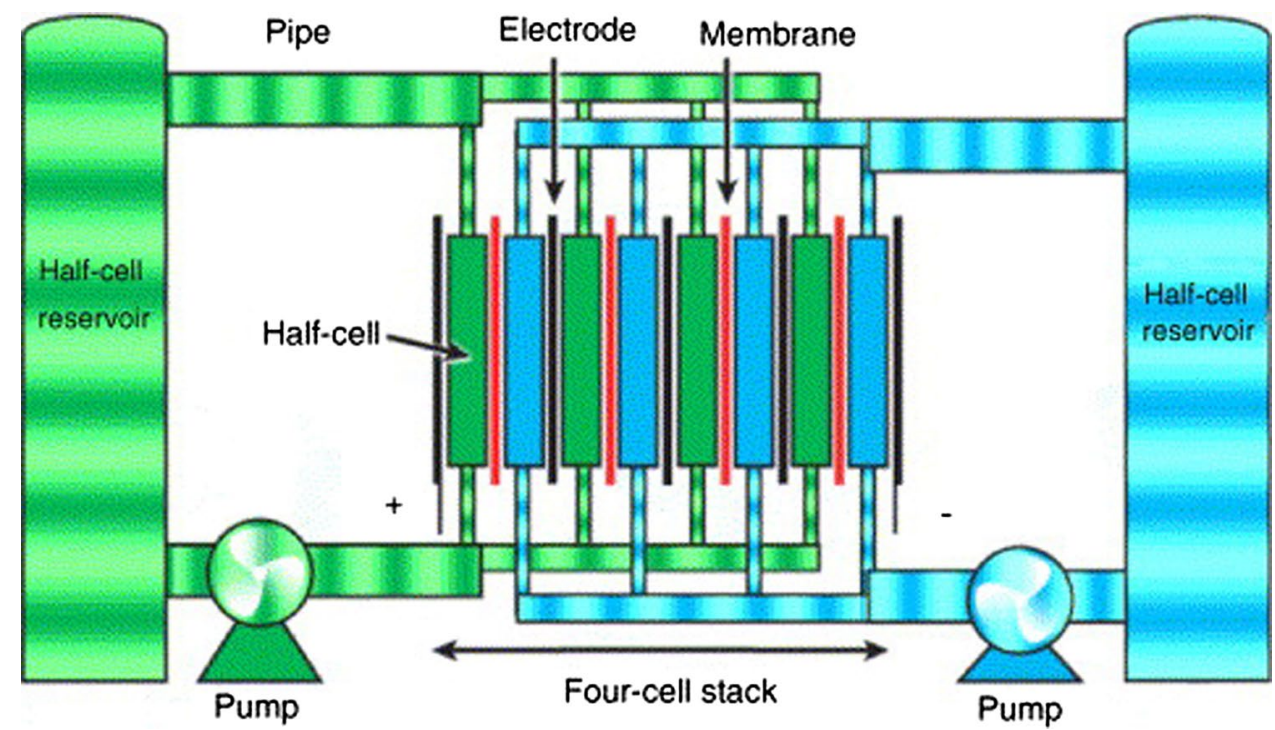


However, this kind of battery requires a large space due to the relatively low energy density of $10-50 \mathrm{Wh} / \mathrm{kg}$. To date, the vanadium redox battery has become one of mature battery technologies for GLEES. For example, a large power plant of vanadium redox batteries was fabricated at Minamihayakita Transformer Station in Abira-Chou, Hokkaido, with a power capacity of $15 \mathrm{MW}$, which can provide power for $4 \mathrm{~h}$. Moreover, the China National Energy Administration approved a vanadium redox battery system of $200 \mathrm{MW}$ capacity in Dalian, China, in 2016 [10].

Polysulfide bromide batteries are another important flow battery technology that operates on the basis of the redox reaction between sodium polysulfides and the sodium polysulfide separated by a cation-selective membrane (e.g., Nafion), as shown in Eq. (7):

$2 \mathrm{Na}_{2} \mathrm{~S}_{2}+\mathrm{NaBr}_{3} \Leftrightarrow \mathrm{Na}_{2} \mathrm{~S}_{4}+3 \mathrm{NaBr} \quad E^{0}=1.36 \mathrm{~V}$

Polysulfide bromide batteries have an energy density of $\sim 30 \mathrm{Wh} / \mathrm{kg}$ and are suitable for voltage and frequency regulation applications for GLEES due to their fast response time. However, this flow battery has a relatively low efficiency of $\sim 60-75 \%$ because of pumping requirements. Moreover, the practical application of polysulfide bromide batteries still face several challenges, such as the high cost of carbon felt, the complicated preparation method of sodium polysulfide, and cross-contamination during long-term battery operation. Regenesys technologies successfully developed and conducted a preliminary commercialization of the normal operation of a polysulfide bromide battery plant with $120 \mathrm{MWh}, 15 \mathrm{MW}$ power capacity at Innogy's Little Barford Power Station in the UK and in Columbus, Mississippi, in the USA [1].

\section{Conclusion and Perspectives}

GLEES, which is the process of converting electricity from a grid-scale power network to a storable form for conversion back to electricity when needed, plays an essential role in the supply-demand balance of electricity generation, distribution, and usage. To date, several energy storage approaches have been developed, such as secondary battery technologies and supercapacitors, flow batteries, flywheels, compressed air energy storage, thermal energy storage, and pumped hydroelectric power. Characterized by modularization, rapid response, flexible installation, and short construction cycles, battery technologies are considered as one of the most desirable electrochemical energy storage devices for GLEES. Generally, energy storage technologies are needed to meet the following requirements of GLEES: (1) peak shaving and load leveling; (2) voltage and frequency regulation; and (3) emergency energy storage. Peak shaving and load leveling is an efficient way to mitigate the peak-to-valley power demand gap between day and night when the battery is charged and discharged to cut the peaks and fill the valleys. Voltage and frequency regulation are utilized in the nonuniform electrical load of the grid network to achieve a real-time electric power and energy balance during the time the battery is used, providing regulation power to the grid by charging and discharging with a fast response time $(<20 \mathrm{~ms})$. In addition, to ensure the smooth development of the national economy and social stability, quick-response batteries are an effective technology for emergency energy storage in GLEES. This work discussed several types of battery energy storage technologies (lead-acid batteries, $\mathrm{Ni}-\mathrm{Cd}$ batteries, $\mathrm{Ni}-\mathrm{MH}$ batteries, $\mathrm{Na}-\mathrm{S}$ batteries, $\mathrm{Li}$-ion batteries, flow batteries) in detail for the application of GLEES to establish a perspective on battery technology and a road map to guide future studies and promote the commercial application of batteries in GLEES. The detailed comparison among these battery technologies with respect to their corresponding characteristics, advantages, and disadvantages for application in GLEES is shown in Fig. 8 and Tables 1, 2.

Despite the considerable progress made so far, many challenges still remain for the development of battery technologies for GLEES. Substantial room and tremendous opportunities exist in the following directions:

(1) Novel battery systems urgently needed to meet the requirement of overall performance. Lead-acid batteries are the least expensive. However, they suffer from a limited depth of discharge, cycle life, and battery efficiency. $\mathrm{Na}-\mathrm{S}$ and flow batteries are hindered by low rates and low energy efficiencies during operation. Current research on the exploration of battery technologies and GLEES is mainly unilateral and pays more attention to the comprehensive development and overall performance of batteries, including energy and power densities, response time, operating temperature, lifetime (cycle and shelf life), battery voltage, energy efficiency, memory effect, safety, environmental friendliness, and cost. The development of a novel battery system requires both fundamental and applied research in multiple fields such as chemistry, materials, battery/ stack design, and battery system engineering to further refresh current technologies and explore new technologies such as $\mathrm{Zn}-\mathrm{Ni}$ batteries and metal-air batteries [50-52].

(2) Cost efficiency plays an important role in the exploration of battery technologies for GLEES. The use of Li-ion batteries in stationary applications is costly. Therefore, ongoing effort is being made to investigate Na-ion batteries due to the potential resource limitations of lithium. For example, Carnegie Mellon University and its spin-off company Aquion Energy supported 


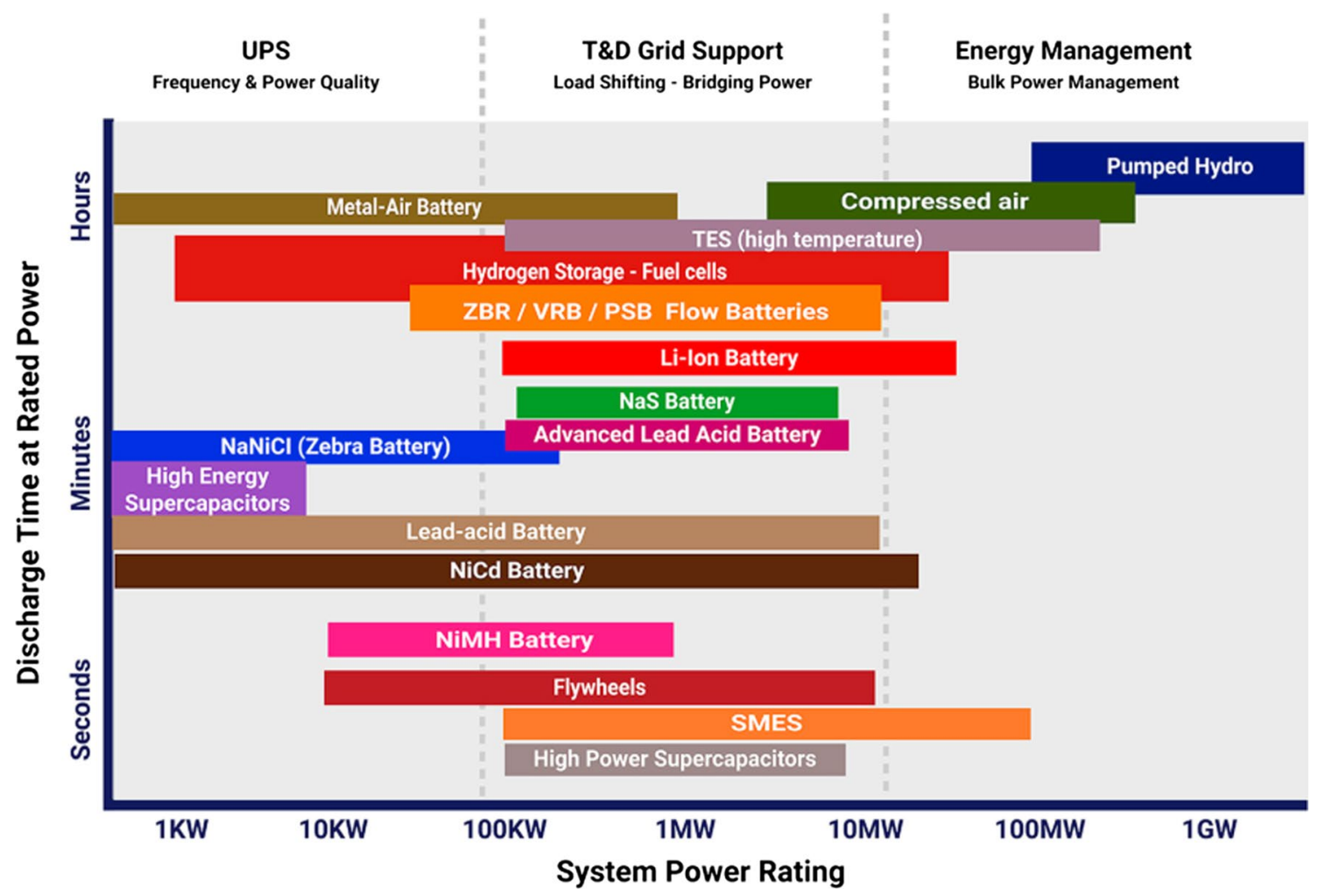

Fig. 8 Comparison of discharge time and power rating for various energy storage technologies. Reproduced with permission [10]. Copyright 2018, Elsevier

by the Department of Energy (DOE) are investigating an aqueous Na-ion battery for GLEES. The Massachusetts Institute of Technology is exploring a lowcost all-liquid-metal battery for GLEES application. Arizona-based Fluidic Energy, which is also supported by the DOE, is studying zinc-air utility batteries with ionic liquid electrolyte for utility applications [34]. In addition, aqueous-based batteries operating with waterbased electrolytes are promising battery systems for GLEES in residential homes and dense urban areas due to their high degree of safety and low cost.

(3) An effective and comprehensive assessment of overall battery technologies is of great importance. Battery energy storage devices used in GLEES are distributed worldwide with different geographical locations, temperature, and environmental conditions. In this case, evaluation of battery performances (e.g., power and energy densities, cycle and shelf life, energy efficiency, response time, operation temperature, safety, environmental friendliness and maintenance fee) and economic and environmental effects should be of significant con- cern to make a comparison and proper selection among various batteries to ensure efficient energy management. The selection of the battery system for GLEES is dependent on various factors. In addition to theoretical analysis, simulations of certain modeling systems under actual operating conditions are also critical for practical applications.

Currently, a number of countries, including the USA, China, and countries in Europe, are increasingly exploring the use of battery energy storage technologies in GLEES. For example, 16 energy storage demonstration projects of the Smart Grid Demonstration are supported by the DOE with a total of $\$ 185$ million in DOE shares plus $\$ 585$ million cost share. The growing interest and global research and development activities indicate a broad prospect for the development of improved battery technologies for the future GLEES. 


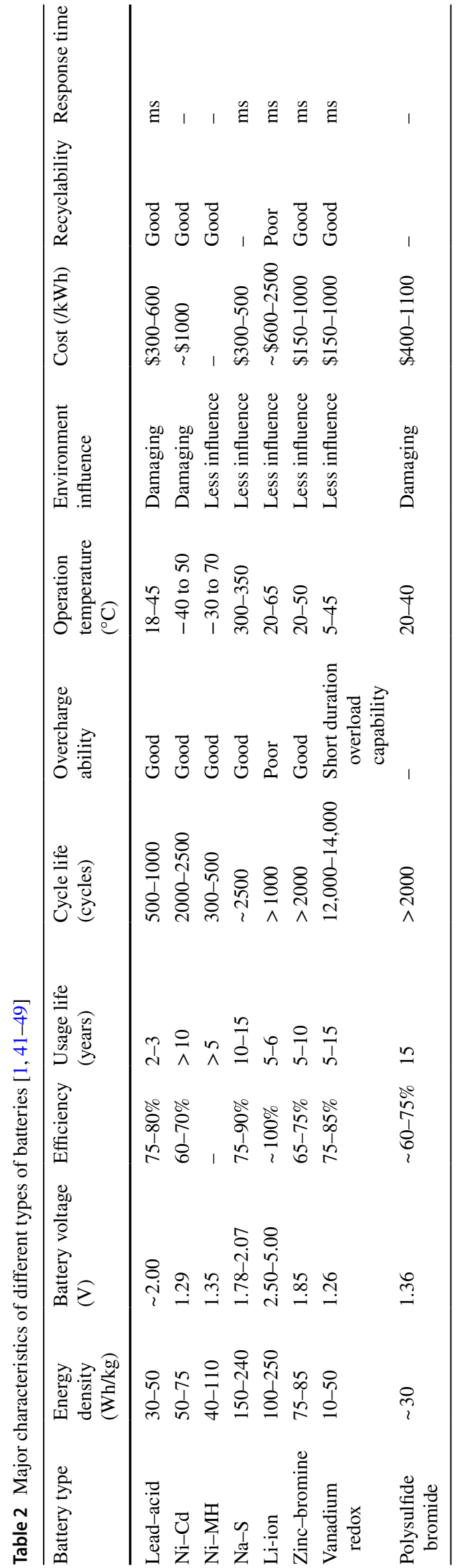

Open Access This article is licensed under a Creative Commons Attribution 4.0 International License, which permits use, sharing, adaptation, distribution and reproduction in any medium or format, as long as you give appropriate credit to the original author(s) and the source, provide a link to the Creative Commons licence, and indicate if changes were made. The images or other third party material in this article are included in the article's Creative Commons licence, unless indicated otherwise in a credit line to the material. If material is not included in the article's Creative Commons licence and your intended use is not permitted by statutory regulation or exceeds the permitted use, you will need to obtain permission directly from the copyright holder. To view a copy of this licence, visit http://creativecommons.org/licenses/by/4.0/.

\section{References}

1. Chen HS, Cong TN, Yang W et al (2009) Progress in electrical energy storage system: a critical review. Prog Nat Sci 19(3):291-312

2. Park M, Ryu J, Wang W et al (2017) Material design and engineering of next-generation flow-battery technologies. Nat Rev Mater 2(1): 16080

3. Xu JQ, Thomas HR, Francis RW et al (2008) A review of processes and technologies for the recycling of lithium-ion secondary batteries. J Power Sour 177(2):512-527

4. Dunn B, Kamath H, Tarascon JM (2011) Electrical energy storage for the grid: a battery of choices. Science 334(6058):928-935

5. Doucette RT, McCulloch MD (2011) A comparison of high-speed flywheels, batteries, and ultracapacitors on the bases of cost and fuel economy as the energy storage system in a fuel cell based hybrid electric vehicle. J Power Sour 196(3):1163-1170

6. Ibrahim H, Ilinca A, Perron J (2008) Energy storage systems: characteristics and comparisons. Renew Sustain Energy Rev 12(5):1221-1250

7. Wang Y-J, Fang BZ, Zhang D et al (2018) A review of carboncomposited materials as air-electrode bifunctional electrocatalysts for metal-air batteries. Electrochem Energy Rev 1(1):1-34

8. Ding J, Liu Z, Liu XR et al (2019) Mesoporous decoration of freestanding palladium nanotube arrays boosts the electrocatalysis capabilities toward formic acid and formate oxidation. Adv Energy Mater 9(25):1900955

9. Ding J, Zhang HL, Zhou H et al (2019) Sulfur-grafted hollow carbon spheres for potassium-ion battery anodes. Adv Mater 31(30): 1900429

10. Argyrou MC, Christodoulides P, Kalogirou SA (2018) Energy storage for electricity generation and related processes: technologies appraisal and grid scale applications. Renew Sustain Energy Rev 94:804-821

11. Fan XY, Liu XR, Hu WB et al (2019) Advances in the development of power supplies for the internet of everything. InfoMat 1(2):130-139

12. Kerestes RJ, Reed GF, Sparacino AR (2012) Economic analysis of grid level energy storage for the application of load leveling. In: 2012 IEEE power and energy society general meeting. New York, USA, pp 1-9

13. Xu BL, Oudalov A, Poland J et al (2014) BESS control strategies for participating in grid frequency regulation. Int Fed Autom Control 47(3):4024-4029

14. Etacheri V, Marom R, Elazari R et al (2011) Challenges in the development of advanced Li-ion batteries: a review. Energy Environ Sci 4(9):3243-3262

15. Oshima T, Kajita M, Okuno A (2004) Development of sodiumsulfur batteries. Int J Appl Ceram Technol 1(3):269-276 
16. Zhang W, Yang JK, Wu X et al (2016) A critical review on secondary lead recycling technology and its prospect. Renew Sustain Energy Rev 61:108-122

17. Feng F, Geng M, Northwood DO (2001) Electrochemical behaviour of intermetallic-based metal hydrides used in $\mathrm{Ni} /$ metal hydride (MH) batteries: a review. Int J Hydrog Energy 26(7):725-734

18. Aurbach D, Gofer Y, Lu Z et al (2001) A short review on the comparison between Li battery systems and rechargeable magnesium battery technology. J Power Sour 97-98:28-32

19. Parasuraman A, Lim TM, Menictas C et al (2013) Review of material research and development for vanadium redox flow battery applications. Electrochim Acta 101:27-40

20. Lu J, Chen ZW, Pan F et al (2018) High-performance anode materials for rechargeable lithium-ion batteries. Electrochem Energy Rev 1(1):35-53

21. Yang XF, Li X, Adair K et al (2018) Structural design of lithiumsulfur batteries: from fundamental research to practical application. Electrochem Energy Rev 1(3):239-293

22. Sun YT, Liu XR, Jiang YM et al (2019) Recent advances and challenges in divalent and multivalent metal electrodes for metal-air batteries. J Mater Chem A 7(31):18183-18208

23. Zhao ZQ, Fan XY, Ding J et al (2019) Challenges in zinc electrodes for alkaline zinc-air batteries: obstacles to commercialization. ACS Energy Lett 4(9):2259-2270

24. Pasta M, Wessells CD, Huggins RA et al (2012) A high-rate and long cycle life aqueous electrolyte battery for grid-scale energy storage. Nat Commun 3:1149

25. Soloveichik GL (2011) Battery technologies for large-scale stationary energy storage. Annu Rev Chem Biomol Eng 2:503-527

26. Zhang C, Wei Y-L, Cao P-F et al (2018) Energy storage system: current studies on batteries and power condition system. Renew Sustain Energy Rev 82:3091-3106

27. Mehr TH, Masoum MAS, Jabalameli N (2013) Grid-connected lithium-ion battery energy storage system for load leveling and peak shaving. In: 2013 Australasian universities power engineering conference (AUPEC), Hobart, Australia, pp 1-6

28. Lazarewicz ML, Rojas A (2004) Grid frequency regulation by recycling electrical energy in flywheels. In: 2004 IEEE power engineering society general meeting, vol 1-2, Denver, CO, USA, pp 2038-2042

29. Zeng B, Ouyang SJ, Zhang JH et al (2015) An analysis of previous blackouts in the world: lessons for China's power industry. Renew Sustain Energy Rev 42:1151-1163

30. van der Vleuten E, Lagendijk V (2010) Transnational infrastructure vulnerability: the historical shaping of the 2006 European "Blackout". Energy Policy 38(4):2042-2052

31. Ahuja R, Blomqvist A, Larsson P et al (2011) Relativity and the lead-acid battery. Phys Rev Lett 106(1):018301

32. Reddy TB (2010) Linden's handbook of batteries. McGraw-hill, New York

33. Saminathan RK (2017) Lead acid battery. Attacking sulphate passivation and cyclability problems. GRIN Publishing, Munich

34. Yang ZG, Zhang JL, Kintner-Meyer MCW et al (2011) Electrochemical energy storage for green grid. Chem Rev 111(5):3577-3613

35. Lach J, Wróbel K, Wróbel J et al (2019) Applications of carbon in lead-acid batteries: a review. J Solid State Electrochem 23(3):693-705

36. Fetcenko MA, Ovshinsky SR, Reichman B et al (2007) Recent advances in NiMH battery technology. J Power Sour 165(2):544-551

37. Ouyang LZ, Huang JL, Wang H et al (2017) Progress of hydrogen storage alloys for $\mathrm{Ni}-\mathrm{MH}$ rechargeable power batteries in electric vehicles: a review. Mater Chem Phys 200:164-178

38. Lu XC, Xia GG, Lemmon JP et al (2010) Advanced materials for sodium-beta alumina batteries: status, challenges and perspectives. J Power Sour 195(9):2431-2442
39. Bachman JC, Muy S, Grimaud A et al (2016) Inorganic solidstate electrolytes for lithium batteries: mechanisms and properties governing ion conduction. Chem Rev 116(1):140-162

40. van der Linden S (2006) Bulk energy storage potential in the USA, current developments and future prospects. Energy 31(15):3446-3457

41. Bukhari SMAS, Maqsood J, Baig MQ et al (2015) Comparison of characteristics: lead acid, nickel based, lead crystal and lithium based batteries. UKSim-AMSS international conference on computer modelling and simulation, Cambridge, United Kingdom, pp 444-450

42. Yao LZ, Yang B, Cui HF et al (2016) Challenges and progresses of energy storage technology and its application in power systems. J Mod Power Syst Clean Energy 4(4):519-528

43. Liu YF, Pan HG, Gao MX et al (2011) Advanced hydrogen storage alloys for $\mathrm{Ni} / \mathrm{MH}$ rechargeable batteries. J Mater Chem 21(13):4743-4755

44. Perrin M, Malbranche P, Lemaire-Potteau E et al (2006) Temperature behaviour: comparison for nine storage technologies: results from the INVESTIRE network. J Power Sour 154(2):545-549

45. Lailler P, Sarrau JF, Sarrazin C (2001) Comparative study for "36 V" vehicle applications: advantages of lead-acid batteries. J Power Sour 95(1-2):58-67

46. Manla E, Nasiri A, Rentel CH et al (2010) Modeling of zinc bromide energy storage for vehicular applications. IEEE Trans Ind Electron 57(2):624-632

47. Rydh CJ (1999) Environmental assessment of vanadium redox and lead-acid batteries for stationary energy storage. J Power Sour 80(1-2):21-29

48. Dehghani-Sanij AR, Tharumalingam E, Dusseault MB et al (2019) Study of energy storage systems and environmental challenges of batteries. Renew Sustain Energy Rev 104:192-208

49. Leung P, Li XH, de Leon $\mathrm{CP}$ et al (2012) Progress in redox flow batteries, remaining challenges and their applications in energy storage. RSC Adv 2(27):10125-10156

50. Liu XR, Yuan YF, Liu J et al (2019) Utilizing solar energy to improve the oxygen evolution reaction kinetics in zinc-air battery. Nat Commun 10:4767

51. Li M, Liu B, Fan XY et al (2019) Long-shelf-life polymer electrolyte based on tetraethylammonium hydroxide for flexible zinc-air batteries. ACS Appl Mater Interfaces 11(32):28909-28917

52. Fan XY, Liu J, Song ZS et al (2019) Porous nanocomposite gel polymer electrolyte with high ionic conductivity and superior electrolyte retention capability for long-cycle-life flexible zinc-air batteries. Nano Energy 56:454-462

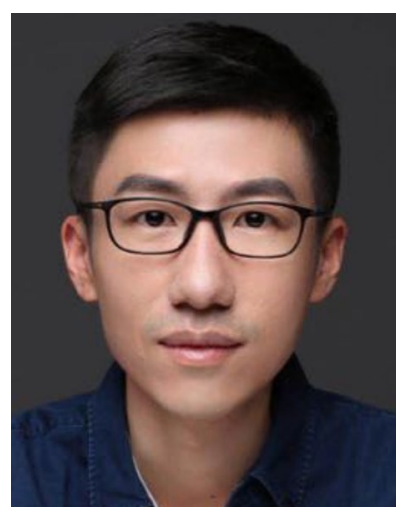

Dr. Cheng Zhong is a Professor in School of Materials Science and Engineering at Tianjin University, the winner of both the National "Ten Thousand Plan" Youth Talent and the National Science Foundation for Excellent Young Scholars, Fellow of Royal Society of Chemistry, a Board Committee Member of the International Academy of Electrochemical Energy Science (IAOEES) and has been awarded as the Distinguished Young Investigator by the IAOEES. He is an associate editor of Frontiers in Chemistry. His recent research interests focus on advanced energy materials and battery electrochemistry, and the development of electrometallurgical methods in the preparation of micro/nanomaterials. 